\title{
Service Ecosystems of cloud computing
}

\author{
Renjun $\mathbf{Q u}{ }^{1}$ Qiongwei Ye ${ }^{1}$ \\ ${ }^{1}$ Business School, Yunnan University of Finance and Economics, Kunming, Yunnan, \\ China
}

\begin{abstract}
In this paper, we consider the Service Ecosystems of cloud computing is emerging. We present the Architecture of cloud computing's Service Ecosystems, and describe Service Ecosystems working mechanism, then analyze the service composition the of Service Ecosystems. Value network is analyzed by identifying five main actors of Service Ecosystems. At last, we give summarizes of this paper.
\end{abstract}

Keywords: Service Ecosystems, cloud computing

\section{Introduction}

Cloud computing has become a very hot term in the last few years, but a clear description of what it is, what it can do, and why companies might use it is often difficult to find. The concept and a number of predecessor technologies have been around for decades. In essence it is a means of renting computers, storage, and network capacity on an hourly basis from some company that already has these resources in their own data center and can make them available to you and your customers via the Internet(Smith, 2009) ${ }^{[1]}$.

Nicholas Carr has suggested that computing will follow electricity generation in the pattern of business use (Carr, 2008) [2]. A hundred years ago, companies stopped generating their own power with steam engines and dynamos and plugged into the newly built electric grid. The cheap power pumped out by electric utilities didn't just change how businesses operate. It set off a chain reaction of economic and social transformations that brought the modern world into existence. A century ago, power generation was a barrier to market entry because of the huge up-front cost to build dedicated factory generation capacity. In the late 20th century, the cost of IT was a similar barrier to new companies. Hooked up to the Internet's global computing grid, massive information-processing plants have begun pumping data and software code into our homes and businesses. Cloud computing offers to eliminate this barrier by turning computing into a utility that companies can purchase based on specific demand.

The shift is already remaking the computer industry, bringing new competitors like Google and Salesforce.com to the fore and threatening stalwarts like Microsoft and Dell. But the effects will reach much further. Cheap, utility-supplied computing will ultimately change society as profoundly as cheap electricity did. We can already see the early effects - in the shift of control over media from institutions to individuals, in debates over the value of privacy, in the export of the jobs of knowledge workers, even in the growing concentration of wealth. As information utilities expand, the changes will only broaden, and their pace will only accelerate (Carr, 2008). ${ }^{[3]}$

Amazon.com has become the leader in providing cloud services to thousands of businesses in the last few years. IT companies like IBM, HP, Sun, Microsoft, and many smaller companies are getting into the business and base their own cloud offerings on the model pioneered by Ama- 
zon. Each offer a unique package of services, security, accessibility, reliability, and support that they feel will appeal to the customers they are interested in (Smith, 2009).

The success of Web-service-centred business models such as Amazon.com, Google, and Salesforce.com demonstrate the real commercial success of these models. Building on their wide-spread use new composite services are created that span across business boundaries in order to implement end-to-end business processes. This phenomenon of a large collection of Web services has been described as a service ecosystem and a growing interest in academic research is emerging as a consequence (Barros et al, 2005; Barros \& Dumas, 2006; Riedl et al., 2008; Riedl et al., 2009; Sawatani, 2007; $\mathrm{Wu} /$ Chang, 2005) ${ }^{[4][5][6][7][8][9] \text {. }}$ [9

A rich ecosystem of Cloud computing services and providers has emerged, forming a complex environment in which Web-scale end-user applications and services are developed, tested, deployed and operated(Lenk, A., et al, 2009). ${ }^{[10]}$ In section 2, we give the architecture of cloud computing service ecosystem.

\section{The Architecture}

As the Web service infrastructure matures and first-generation SOAs move to the mainstream, a new revolution in serviceorientation is emerging. Web service providers are interconnecting their offerings in unforeseen ways, giving rise to Web service ecosystems (Barros et al, 2005; Barros \& Dumas, 2006). A Web service ecosystem is a logical collection of Web services whose exposure and access are subject to constraints characteristic of business service delivery. In these ecosystems, service consumers procure services through different distribution and delivery channels, outsourcing service delivery functions such as payment, au- thentication, and mediation to specialist intermediaries. Web service ecosystems make explicit the notion of service procurement, separating it from that of conventional service supply.

There are many definitions of cloud computing. Youseff et al. were among the first who tried to provide a comprehensive understanding of cloud computing and all its relevant components. They regard cloud computing as a "collection of many old and few new concepts in several research fields like Service- Oriented Architectures (SOA), distributed and grid computing as well as Virtualization" (Youseff et al. 2008) ${ }^{[11]}$. According to Youseff et al. "cloud computing can be considered a new computing paradigm that allows users to temporary utilize computing infrastructure over the network, supplied as a service by the cloudprovider at possibly one or more levels of abstraction" (Youseff et al. 2008). According to Armbrust et al. "Cloud Computing refers to both the applications delivered as services over the Internet and the hardware and systems software in the datacenters that provide those services. The services themselves have long been referred to as Software as a Service (SaaS). The datacenter hardware and software is what we will call a Cloud. When a Cloud is made available in a payas-you-go manner to the general public, we call it a Public Cloud; the service being sold is Utility Computing. We use the term Private Cloud to refer to internal datacenters of a business or other organization, not made available to the general public. Thus, Cloud Computing is the sum of SaaS and Utility Computing, but does not include Private Clouds" (Armbrust et al. 2009) ${ }^{[12]}$. In this way the authors as well understand cloud computing as a collective term, covering preexisting computing concepts such as SaaS and utility computing. Being grid computing scholars, Buyya et al. postulate a 
more technical focused approach, regarding cloud computing as a kind of parallel and distributed system, consisting of a collection of virtualized computers. This system provides resources dynamically, whereas Service Level Agreements (SLA) are negotiated between the service provider and the customer (Buyya et al. 2008) ${ }^{[13]}$.In an attempt to provide a generally accepted definition, Vaquero et al. have derived similarities, based on Geelan's collection of expert opinions (Geelan 2009) ${ }^{[14]}$. They claim that "clouds are a large pool of easily usable and accessible virtualized resources (such as hardware, development platforms and/or services). These resources can be dynamically reconfigured to adjust to a variable load (scale), allowing also for an optimum resource utilization. This pool of resources is typically exploited by a pay-per-use model in which guarantees are offered by the Infrastructure Provider by means of customized SLAs" (Vaquero et al. 2009). Based on literature review and perception of cloud computing, München ${ }^{[15]}$ provide a definition that regards the concept holistically, from both the application and infrastructure perspective, which focus on the deployment of computing resources and applications, rather than on a technical description. München's definition stresses the ability of service-composition, allowing service providers to create new services by aggregating existing services, enabling customized solutions and varying distribution models. München consider cloud computing as an IT deployment model, based on virtualization, where resources, in terms of infrastructure, applications and data are deployed via the internet as a distributed service by one or several service providers. These services are scalable on demand and can be priced on a pay-per-use basis.US National Institute of Standards and Technology (NIST) 's definition has captured the commonly agreed aspects of cloud computing; it defines cloud computing as "a model for enabling convenient, on-demand network access to a shared pool of configurable computing resources (e.g., networks, servers, storage, applications, and services) that can be rapidly provisioned and released with minimal management effort or service provider interaction"(Mell \& Grance, 2009) ${ }^{[16]}$.

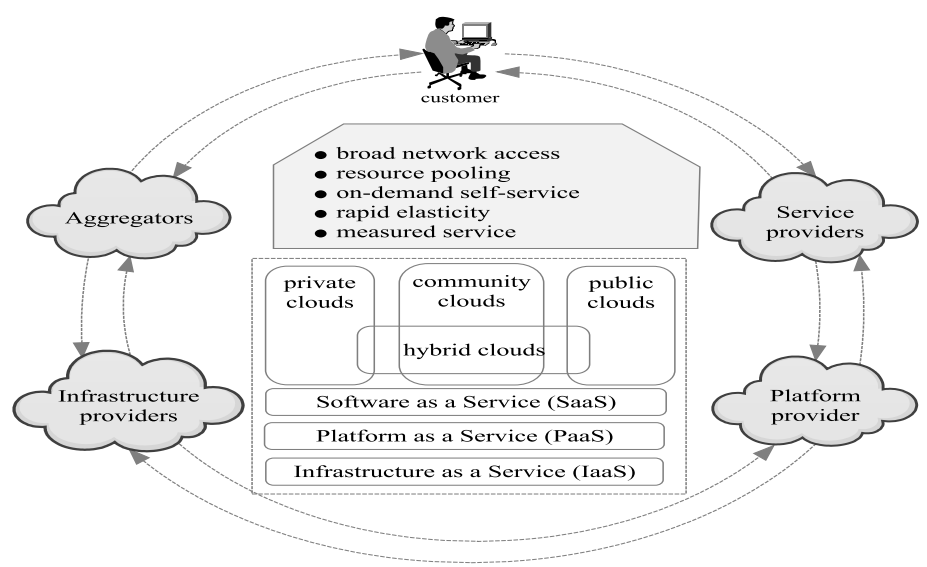

Fig. 1: service ecosystems of cloud computing. 
Based on above definitions and analysis, we consider the cloud computing as service ecosystems in which everything is service, and Through the increased service orientation and the opportunities of offering services on general cloud computing platforms provided by other providers as well as the new opportunities to integrate individual component services to create value-added, complex services gave rise to a set of new roles that can be found in cloud computing. So the architecture of service ecosystems show as figure 1 .

So in this paper, Section 3 describes Service Ecosystems working mechanism. Section 4 discuss the topic about everything is service in the Service Ecosystems. Section 5 is about the actor of Service Ecosystems.

\section{Service Ecosystems Mechanism}

In Moore's opinion, Ecosystems is the third form of coordinating production follow Markets and Hierarchies (Moore, 2005) ${ }^{[17]}$.

Markets facilitate transactions for goods. Hierarchies facilitate control over activities that produce goods. Ecosystems facilitate coordination of innovation in goods and the activities that produce them, as well facilitate managed coevolution of the complex web of markets and hierarchies themselves. What differ, in the three forms of organization, are the ideal relationships that are sought, and the levels of analysis used to judge performance. In markets, the ideal is perfectly transparent transactions for contributions, i.e. goods and services. In hierarchies, the ideal is perfect control of tasks. In business ecosystems, the ideal is perfect coevolution of innovation across a multitude of contributors.

Moore give a three order of business evolution which moves forward from a first order consideration of exchanges, to a second order focus on activities, to a third order emphasis on the ideas that guide activities: on designs, paradigms, patterns, and the trajectories of innovation that inventive contributors can imagine(Moore, 2005). The first order of consideration is the "invisible hand" of the market (Smith, 1776) ${ }^{[18]}$. The second order of consideration is the "visible hand" of the firm (Chandler ,1980) ${ }^{[19]}$. The third order of consideration might be termed the "visible imagination" because the transactions that are coordinated are not primarily for goods or activities, but for commitments to the future. A business ecosystem is a distinct managerial approach for coordinating the co-evolution of agency, agency concerned with intraand-intermarket improvement in goods and services, and with intra-and-interfirm improvement in activities.

Eymann et al present us with An investigation of implementing an electronic Grid market based on the "Catallaxy" concept of F.A. von Hayek (Eymann et al, 2005) ${ }^{[20]}$. This market makes use of a "free market" economic self-organisation approach in the context of electronic services. A key issue is to utilize this approach as the basis for realizing resource allocation in Application Layer Networks (ALNs).

Hayek's work provides concrete insight on the working mechanisms of economic coordination. The emergence of software agent technology and increasing us of virtualization leads to the possibility of implementing Hayek's Catallaxy concept and using the ensuing "spontaneous order" as a concrete proposal for both the design and coordination cloud computing. The Catallaxy concept is based on the explicit assumption of self-interested actions of the participants, who try to maximize their own utility and choose their actions under incomplete information and bounded rationality (Simon, 1957) ${ }^{[21]}$. The term Catallaxy comes from 
the Greek word "katallatein", which means, "to barter" and at the same time, "to join a community." The goal of Catallaxy is to arrive at a state of coordinated actions, through the bartering and communicating of members, to achieve a community goal that no single user has planned for.

The main characteristics of the Catallaxy( Hoppmann, 1999) ${ }^{[22]}$ are enumerate as:(1)Participants work for their own interest to gain income;(2) Participants can only estimate the effect of action alternatives on an income or utility maximization goal;(3) Participants communicate using commonly accessible markets, where they barter about access to resources held by other participants.

In the service Ecosystems of cloud computing, Catallactic agents follow the economic goal of profit maximization. They try to buy input goods for less and to sell output goods for more. Depending on the current market situation, its equity, and stock, the agent decides autonomously which action to take next - whether to buy, sell, produce, move or self-terminate.

The agent lifecycle "follows the money"(Ardaiz et al, 2006) ${ }^{[23]}$ : if the agent has finished goods in stock, it tries to sell. If the agent has no goods, but input factors in stock, it stimulates the production of output goods (by waiting an appropriate length of time). If the agent has no input factors in stock, it tries to buy some. If the market situation is completely satisfying, e.g. if there are no offers or demands within a certain time span, the agent tries to move to another marketplace. If the agent has spent its entire budget or all marketplaces are shut down, it has to terminate - every few milliseconds the agent has to pay utilization fees to the market anyway, so doing nothing is never a rewarding strategy. In the case of buying or selling, the software agent goes through the three stages of a market transaction: information, agreement, and settlement. In the information phase of any transaction, a buyer or seller has to identify his or her potential trading partners. The buyer agent initiates the agreement phase by communicating with a supplier. Both software agents negotiate using a monotonic concession protocol, where propose and counter-propose messages with subsequent price concessions are exchanged. If the negotiation process is successful, both agents will reach a compromise price agreement; otherwise, someone will sooner or later drop out of the negotiation. In this event, the agents will restart with other partners. In the final settlement phase, the transaction is carried out and monitored. Sellers and buyers exchange goods and money, respectively.

In section5, we'll describe 5 kind of agent. Which is customer, service provider, aggregators (Kohlborn, T., et al, 2009), platform provider and infrastructure provider.

\section{The Composition of Cloud Compu- ting}

On the technical side, service ecosystems refer to a logical web service collection (Barros \& Dumas, 2006), with more than one service provider. On the business side, service ecosystems bring together shared information, people, and technology (Spohrer, 2007) ${ }^{[24]}$. They comprise service innovation, service design, service engineering, service marketing, and service provisioning (Kett et al) ${ }^{[25]}$.

The NIST model describes cloud computing as being composed of Three service models, Four deployment models and Five characteristics (Mell \& Grance, 2009). ${ }^{[26]}$

The three service Models include Cloud Software as a Service (SaaS), which refer to the capability provided to the consumer is to use the provider's applications running on a cloud 
infrastructure, the applications are accessible from various client devices through a thin client interface such as a web browser (e.g., web-based email); Cloud Platform as a Service (PaaS), which means the capability provided to the consumer is to deploy onto the cloud infrastructure consumer-created or acquired applications created using programming languages and tools supported by the provider; Cloud Infrastructure as a Service (IaaS) is described as the capability provided to the consumer is to provision processing, storage, networks, and other fundamental computing resources where the consumer is able to deploy and run arbitrary software, which can include operating systems and applications.

Four deployment models is consist of Private cloud, which is operated solely for an organization, It may be managed by the organization or a third party and may exist on premise or off premise; Community cloud, The cloud infrastructure is shared by several organizations and supports a specific community that has shared concerns (e.g., mission, security requirements, policy, and compliance considerations); Public cloud, The cloud infrastructure is made available to the general public or a large industry group and is owned by an organization selling cloud services; Hybrid cloud, The cloud infrastructure is a composition of two or more clouds (private, community, or public) that remain unique entities but are bound together by standardized or proprietary technology that enables data and application portability (e.g., cloud bursting for load-balancing between clouds).

\begin{tabular}{|l|l|l|l|}
\hline Category & Characteristics & Product Type & Vendors \& Products \\
\hline SaaS & $\begin{array}{l}\text { Customers are provided } \\
\text { with applications that } \\
\text { are accessible anytime } \\
\text { and from anywhere. }\end{array}$ & $\begin{array}{l}\text { Web applications } \\
\text { and services (Web } \\
2.0)\end{array}$ & $\begin{array}{l}\text { SalesForce.com (CRM); } \\
\text { Clarizen.com; (Project Man- } \\
\text { agement); Google Documents, } \\
\text { Google Mail (Automation) }\end{array}$ \\
\hline PaaS & $\begin{array}{l}\text { Customers are provided } \\
\text { with a platform for de- } \\
\text { veloping applications } \\
\text { hosted in the Cloud. }\end{array}$ & $\begin{array}{l}\text { Programming APIs } \\
\text { and frameworks; } \\
\text { Deployment system. }\end{array}$ & $\begin{array}{l}\text { Google AppEngine; } \\
\text { Microsoft Azure; } \\
\text { Manjrasoft Aneka }\end{array}$ \\
\hline IaaS/HaaS & $\begin{array}{l}\text { Customers are provided } \\
\text { with virtualized hard- } \\
\text { ware and storage on top } \\
\text { of which they can build } \\
\text { their infrastructure. }\end{array}$ & $\begin{array}{l}\text { Virtual machines } \\
\text { management infra- } \\
\text { structure, Storage } \\
\text { management }\end{array}$ & $\begin{array}{l}\text { Amazon EC2 and S3; } \\
\text { GoGrid; Nirvanix }\end{array}$ \\
\hline
\end{tabular}

Table 1: Cloud computing services classification (Buyya et al, 2009) ${ }^{[27]}$.

The five characteristics is On-demand self-service, which means A consumer can unilaterally provision computing capabilities, such as server time and network storage, as needed automatically without requiring human interaction with each service's provider; Broad network access refer to Capabilities are available over the network and accessed through standard mechanisms that promote use by heterogeneous thin or thick client plat- forms (e.g., mobile phones, laptops, and PDAs); Resource pooling means the provider's computing resources are pooled to serve multiple consumers using a multitenant model, with different physical and virtual resources dynamically assigned and reassigned according to consumer demand; Rapid elasticity imply that capabilities can be rapidly and elastically provisioned, in some cases automatically, to quickly scale out and rapidly released to 
quickly scale in.; Measured Service means that cloud systems automaticallycontrol and optimize resource use by leveraging a metering capability at some level of abstraction appropriate to the type of service (e.g., storage, processing, bandwidth, and active user accounts).

NISTs model imply that The five characteristics should be seem as the intermediary between customer and three service models as well as four deployment models, as showed in figure 1 . It is quite uncommon for a single value offering to encompass all the customer's demand. More likely, different vendors specialize their business towards providing a specific subclass of services that address the needs of a market sector customer, so it is possible to characterize the different solutions into the three service Models. Table 1 summarizes the nature of these categories and lists some major players in the field.

\section{The value network of Cloud compu- ting service ecosystem}

From the service ecosystem model described in section 2, we can derive five major actors within the value network: The customer, the service provider, Aggregators (Kohlborn, T., et al, 2009) [28], the platform provider and the infrastructure provider.

The customer buys services through various distribution channels, for example, directly from the service provider or through a platform provider. Corresponding roles are found, for example, in Barros \& Dumas (2006) ${ }^{[29]}$, Riedl et al. (2009) or Haupt (2003).

Service providers, also labeled IT vendors, develops applications that are offered and deployed on the cloud computing platform and offer value to the customer and an aggregate services provider respectively. They access hardware and infrastructure of the infrastructure pro- viders. For example, Tapscott et al. call this role "content provider"(Tapscott \& Lowy, 2000) ${ }^{[30]}$ and Haupt "manufacturer"'(Haupt, 2003).

As we especially want to highlight the aspect of service composition, we have added the aggregator role to the simplified cloud computing value network depicted in Figure 1. The aggregator offering new services or solutions to customer by combining preexisting services. Therefore, they are both a customer (from the perspective of the service provider) and a service provider (from the perspective of the customer). Barros and Dumas call that role "service broker"(Barros \& Dumas, 2006), Haupt calls that an "assembler"(Haupt, 2003). Aggregators that focus on the integration of data rather than services are called data integrators. They ensure that already existing data is prepared and is usable by different cloud services and can be regarded as a sub-role of aggregators with a straightforward focus on technical data integration.

The platform provider offers an environment within which cloud applications can be deployed. He also acts as some kind of catalogue or market within which applications are offered to the customer through one simple portal. The platform provider offers the technical basis for the marketplace where the services are offered.

Infrastructure providers provide the technical backbone and supplies the value network with all the computing and storage services needed to run applications within the cloud.. They offer the necessary, scalable hardware for the services (Tapscott \& Lowy, 2000) upon which the service providers offer their services. Infrastructure providers are sometimes also called IT vendors.

Within this value network, value is created by providing services that are valuable for other participants of the network. Infrastructure services for example 
are essential for all other actors within the value network, who consume this service to provide their service offering. All the actors within the value network exchange services for money add value for other actors through service refinement and eventually provide services that fulfill the customers' needs. As it can be observed in practice, one company can of course act in more than one role. Salesforce for example is a platform provider (AppExchange) and application provider (CRM) at the same time ${ }^{1}$. It can also host its own infrastructure or partly source it from third party infrastructure providers. Various service providers can offer their applications on the Salesforce platform which customers can utilize in conjunction with or separately of Salesforce's CRM solution. Aggregators might combine different services to easily provide a customized solution for the customer.

An architecture must support the management of the ecosystem of Cloud Computing. The ecosystem includes all involved services and solutions vendors, partners, and end users to provide or consumer shared resources in the Cloud Computing environment. Cloud vendors expose its interaction interfaces of its internal operations and product development capability to the cloud. Cloud partners provide components to cloud vendors or serve as agents to provide valueadded services to the cloud clients. Cloud clients are users of the cloud services that offer business goal driven resource sharing.

In Zhang \& Zhou's ${ }^{[31]}$ opinion, the ecosystem should set vendor dashboard, partner dashboard and client dashboard. Cloud vendor dashboard provides an integrated view of interaction with vendors' frontend and backend operations. Since most of the cloud vendors do not work alone anymore, they need to collaborate

\footnotetext{
${ }^{1}$ http://www.salesforce.com
}

with their partners in the value chain of Cloud Computing environment. In this regard, a partner dashboard is needed for the participating partners to interact with the cloud vendors and clients. The cloud client dashboard provides a focal point for all kinds of users to interact with Cloud Computing services or offerings. Putting all those dashboards together, the Cloud Computing ecosystem management layer provides an integrated onboarding process and common utilities to support the seamless collaboration and message exchanges among cloud vendors, partners, and clients.

\section{A Case Study}

Salesforce (www.salesforce.com) leverages software components from the open development community through AppExchange. AppExchange expands Salesforce's customer relationship management software into a larger business software portfolio and exposes this portfolio as a collection of services. Developers can code against Salesforce services using AppExchange testing and deployment tools. Salesforce can then absorb the most fitting compliant software components from third-party developers. This also encourages further avenues of procurement through open publication of Salesforce Web services and integration with other components. For example, NetSuite (www. netsuite.com) integrates Salesforce services with its enterprise resource planning (ERP) and portal solutions, thereby competing with Salesforce's value-added layer. As a result, AppExchange will likely foment a comprehensive enterprise applications marketplace.

There are other forms of open procurement in emerging service marketplace solutions. StrikeIron, for example, supports a repertoire of service delivery functions, including customer account 
management, search, purchasing, and authentication. Third parties and established intermediaries can hook into and supplement this functionality. For example, Salesforce telecall listing service is available through StrikeIron. Likewise, StrikeIron's partnership with Dreambuilder enables extensions through US government services for address, phone number, and taxation verifications.

\section{Summary and Conclusion}

Cloud computing is a new and promising paradigm delivering IT services as computing utilities. As Clouds are designed to provide services to external users, providers need to be compensated for sharing their resources and capabilities. In this paper, we consider the Service Ecosystems of cloud computing is emerging. We give the Architecture of cloud computing's Service Ecosystems, and describes Service Ecosystems mechanism, then analyze the service composition the of Service Ecosystems. Section 5 is about the actor of Service Ecosystems. at last, summarizes and concludes the paper.

\section{References}

[1] Smith, R., "Computing in the Cloud. Research Technology Management," 2009. 52(5): p. 65-68.

[2] Carr, N. (2008). Big switch: Rewiring the world, from Edison to Google. New York: Norton.

[3] Carr, N. (2008). The Big Switch: Rewiring the world from Edison to Google.W.W. Norton \& Co. http://www.nicholasgcarr.com/bigswi tch/

[4] Barros, A.; Dumas, M. \& Bruza, P. "The Move to Web Service Ecosystems". BPTrends, 1-9,2005.

[5] Barros, A. \& Dumas, M. "The Rise of Web Service Ecosystems". IEEE IT Professional, 8(5), 31-37,2006.
[6] Riedl, C.; Böhmann, T.; Rosemann, M. \& Krcmar, H. "Quality Aspects in Service Ecosystems: Areas for Exploitation and Exploration". In: Proceedings of International Conference on Electronic Commerce 2008 (ICEC08), Innsbruck.

[7] Riedl, C.; Böhmann, T.; Rosemann, M. \& Krcmar, H. "Quality Management in Service Ecosystems". Information Systems and e-Business Management (ISeB), 7(2), 199-221,2009.

[8] Sawatani, Y. "Research in Service Ecosystems". In: Proceedings of Portland International Center for Management of Engineering and Technology, 2763-2768,2007.

[9] Wu, C. \& Chang, E. "A conceptual architecture of distributed web services for service ecosystems". In: Proceedings of 18th International Conference on Computer Applications in Industry and Engineering (CAINE), 209-214,2005.

[10] Lenk, A., et al. "What's inside the Cloud? An architectural map of the Cloud landscape". IEEE Computer Society, 2009

[11] Youseff, L., M. Butrico and D. Da Silva "Toward a Unified Ontology of Cloud Computing". Grid Computing Environments Workshop, p. 110,2008.

[12] Armbrust, M., A. Fox, R. Griffith, A. D. Joseph, R. Katz, A. Konwinski, G. Lee, D. Patterson, A. Rabkin, I. Stoica and M. Zaharia."Above the Clouds: A Berkeley View of Cloud Computing". EECS Department, University of California, Berkeley. 2009.

[13] Buyya, R., C. S. Yeo and S. Venugopal . "Market-oriented cloud computing: Vision, hype, and reality for delivering it services as computing utilities". International Conference on High Performance Compu- 
ting and Communications IEEE Computer Society. 2008

[14] Geelan, J. "Twenty-One Experts Define Cloud Computing". Virtualization Journal SYS-CON Media.2009

[15] München, D.E., The Business Perspective of Cloud Computing:Actors, Roles, and Value Networks.http://home.in.tum.de/ riedlc/r es/LeimeisterEtAl2010-preprint.pdf.

[16] P. Mell and T. Grance. "The NIST Definition of Cloud Computing," National Institute of Standards and Technology (2009)

[17] Moore, J.F. "Business ecosystems and the view from the firm". Antitrust Bulletin, 2005. 51(1): p. 31-75.

[18] Adam Smith. An Inquire into the Nature and Causes of the Wealth of Nations. 1776.

[19] Alfred Chandler. The Visible Hand: The Managerial Revolution in American Business.1980.

[20] Eymann T, Reinicke M, Streitberger W, et al. "Catallaxy-based grid markets"[J]. Multiagent and Grid Systems. 2005, 1(4): 297-307.

[21] H. A. Simon, "Models of Man Social and Rational", John Wiley and Sons, 1957

[22] E. Hoppmann, "Unwissenheit, Wirtschaftsordnung und Staatsgewalt", in V. Vanberg (eds), "Freiheit, Wettbewerb und Wirtschaftsordnung", Haufe Verlag, 1999

[23] Ardaiz O, Artigas P, Eymann T, et al. "The catallaxy approach for decentralized economic-based allocation in grid resource and service mar-
kets"[J]. Applied Intelligence. 2006, 25(2): 131-145.

[24] J. Spohrer, P. P. Maglio, J. Bailey, and D. Gruhl. "Steps toward a science of service systems". IEEE Computer, 40(1):71-77, Jan. 2007.

[25] H. Kett, K. Voigt, G. Scheithauer, and J. Cardoso. "Service Engineering for Business Service Ecosystems". In Proceedings of the XVIII. International RESER Conference, Stuttgart, Germany, September 2008.

[26] P. Mell and T. Grance. "The NIST Definition of Cloud Computing," National Institute of Standards and Technology (2009)

[27] Buyya R, Pandey S, Vecchiola C. "Cloudbus toolkit for market-oriented cloud computing"[J]. Cloud Computing. 2009: 24-44

[28] Kohlborn, T., et al. "Service aggregators in business networks". in Proceedings of 1st Workshop on Service-Oriented Business Networks and Ecosystems, 1-4 September. 2009. University of Auckland, New Zealand. [29] Barros, A. P.M. Dumas."The Rise of Web Service Ecosystems". IT Professional, 2006 Vol. 8, Nr. 5, p. 31-37.

[30] Tapscott, D. \& D. Ticolla. Lowy (2000). " Digital capital: harnessing the power of business Webs". Ubiquity, 2000 Vol. 1, Nr. 13.

[31] Zhang, L.J. and Q. Zhou, "CCOA: Cloud computing open architecture". in 2009 IEEE International Conference on Web Services. 2009, Ieee. p. 607-616. 